\title{
Combination of 2-Deoxyglucose and Snail-gut Enzyme Treatments for Preparing Sphaeroplasts of Schizosaccharomyces pombe
}

\author{
By FRANCOISE FOURY AND A. GOFFEAU \\ Euratom Laboratory of Enzymology, University of Louvain, \\ Heverlee, 3030, Belgium
}

(Received 17 May 1972; revised 2 August 1972)

Havelkova (1966), Rost (1969) and Shahin (1971) isolated sphaeroplasts from Schizosaccharomyces pombe by using snail-gut enzymes. However, yields were usually low, and certain strains were not sensitive to snail-gut enzymes especially when grown in glucosecontaining medium. Sphaeroplasts of Schiz. pombe canal so be obtained by using 2-deoxyglucose (2-DG) (Megnet, I965; Johnson \& Rupert, I967; Johnson, I968; Johnson, I969). Recently Birnboim (I 97I) described a new method for preparing sphaeroplasts of Schiz. pombe $972 \mathrm{~h}^{-}$at $0^{\circ} \mathrm{C}$ by snail-gut enzymes after prior adaptation to $70 \mu \mathrm{g} 2-\mathrm{DG} / \mathrm{ml}$ by subculturing the cells daily into medium containing increasing concentrations of 2-DG. Using this method, $10^{7}$ organisms $/ \mathrm{ml}$ can be treated by $\mathrm{I} \%$ snail-gut enzyme.

In this paper, we report that in Schizosaccharomyces pombe, sphaeroplasts obtained by 2-DG lose their respiratory capacity. It appears that long treatments with 2-DG increase the risks of possible metabolic perturbations as well as selection of 2-DG-resistant clones. However, short pre-incubation of growing organisms with 2-DG has no influence on respiration, and greatly facilitates subsequent hydrolysis of walls of four different strains of Schiz. pombe by snail-gut enzymes. Under these conditions $10^{9}$ organisms $/ \mathrm{ml}$ can be efficiently treated with I \% snail-gut enzyme.

\section{METHODS}

The YPDG medium contains: $3.6 \%(\mathrm{w} / \mathrm{v})$ glycerol, $0.1 \%(\mathrm{w} / \mathrm{v})$ glucose, $2 \%(\mathrm{w} / \mathrm{v})$ yeast extract, $2 \%(\mathrm{w} / \mathrm{v})$ bactopeptone. The GLU medium contains; $5.8 \%(\mathrm{w} / \mathrm{v})$ glucose, $2 \%$ $(\mathrm{w} / \mathrm{v})$ yeast extract, $2 \%(\mathrm{w} / \mathrm{v})$ bactopeptone. All media were brought to $\mathrm{pH} 4.5$ with $\mathrm{HCl}$. To prepare sphaeroplasts of Schizosaccharomyces pombe $972 \mathrm{~h}^{-}, 100 \mu \mathrm{g} 2-\mathrm{DG} / \mathrm{ml}$ (in YPDG medium) or $250 \mu \mathrm{g} 2-\mathrm{DG} / \mathrm{ml}$ (in GLU medium) were included in the medium of cultures at the end of exponential phase of growth. Organisms were harvested 20 min later in GLU medium and $30 \mathrm{~min}$ later in YPDG medium, before sphaeroplasts were visible. Organisms, washed twice with cold sterile water, were incubated at room temperature with continuous shaking for $30 \mathrm{~min}$ in $\mathrm{O} . \mathrm{I} \mathrm{M}$-tris- $\mathrm{HCl}(\mathrm{pH} 8.0$ ), $0.5 \mathrm{M}$-sorbitol and $0.3 \mathrm{M}$ - $\beta$-mercaptoethanol. After centrifugation at $2500 \mathrm{~g}$ for $10 \mathrm{~min}$, they were diluted to $10^{9}$ organisms $/ \mathrm{ml}$ in 1 M-sorbitol and incubated at $30{ }^{\circ} \mathrm{C}$ with continuous shaking, in the presence of $\mathrm{I} \%$ glusulase (Endo Laboratories, Garden City, New York, U.S.A.) or I \% helicase (Industrie Biologique Française, Villeneuve-la-Garonne, France). The rate of the enzyme action was measured by lysis in samples diluted with water. Organisms were harvested and washed twice in I M-sorbitol, when $75 \%$ of them were transformed in sphaeroplasts. 


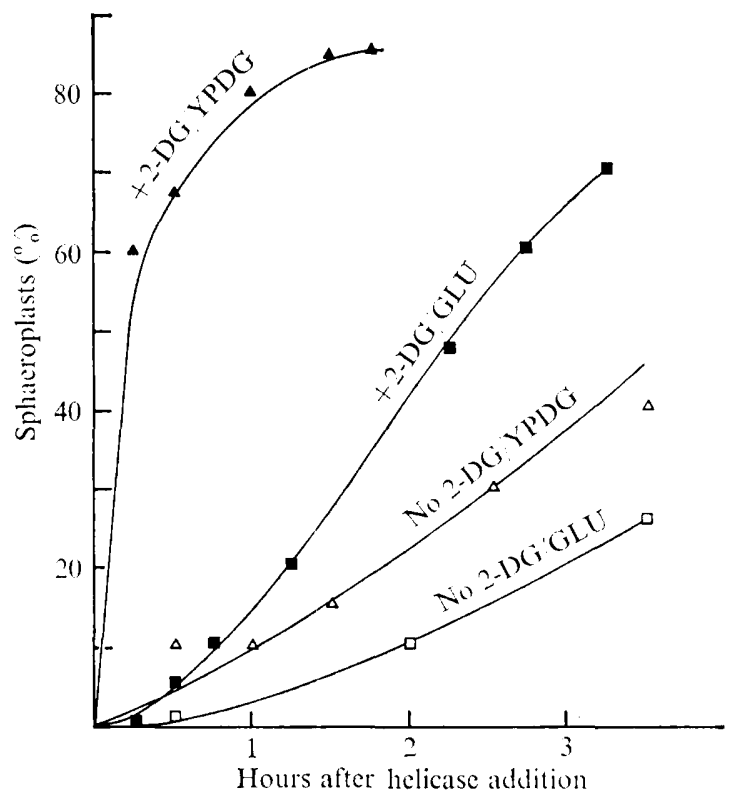

Fig. I. Effect of 2-DG pretreatment on sphaeroplast formation from Schizosaccharomyces pombe by helicase. In 2-DG pretreated cultures, $0.15 \%$ glucose and $100 \mu \mathrm{g} 2-\mathrm{DG} / \mathrm{ml}$ were added to six $10^{7}$ organisms $/ \mathrm{ml}$ in YPDG medium (triangles) and $250 \mu \mathrm{g} 2-\mathrm{DG} / \mathrm{ml}$ were added to $10^{8}$ organisms $/ \mathrm{ml}$ in GLU medium (squares). Organisms were harvested after $30 \mathrm{~min}$ of incubation in GLU medium and 20 min of incubation in YPDG medium, before sphaeroplasts were visible. Organisms were treated with $\beta$-mercaptoethanol and $2 \%$ helicase. Open symbols indicate behaviour of cultures not supplemented with 2-DG.

\section{RESULTS AND DISCUSSION}

Preparation of sphaeroplasts by 2-DG. When added at the beginning of the culture, 2-DG inhibited growth of Schizosaccharomyces pombe $972 \mathrm{~h}^{-}$. In $24 \mathrm{~h}$, I $\mu \mathrm{g}$ of 2-DG/ml inhibited growth by $50 \%$ in glycerol-containing medium. The same degree of inhibition required $100 \mu \mathrm{g} / \mathrm{ml}$ in glucose-containing medium. Addition of 2-DG to media at the end of the exponential phase of growth allowed rapid inhibition of growth, followed by sphaeroplast formation both in glucose- and glycerol-containing media. In glycerol-containing medium addition of $0.15 \%$ glucose just before introduction of 2-DG greatly speeded the sphaeroplast formation. Two hours after addition of $100 \mu \mathrm{g} 2-\mathrm{DG} / \mathrm{ml}$ plus $0.15 \%$ glucose to Schiz. pombe $972 \mathrm{~h}^{-}$growing in glycerol-containing medium, $95 \%$ of the organisms were converted to sphaeroplast but the respiration rate dropped from 200 to $40 \mu \mathrm{IO}_{2} \mathrm{~h}^{-1}$ (IO ( $^{8}$ cells) ${ }^{-1}$. Similar decreases in respiratory rate were observed under every condition producing sphaeroplasts by the sole use of 2-DG.

\section{Combined actions of 2-DG and snail-gut enzyme}

Short pretreatment with 2-DG largely amplified subsequent attack by snail-gut enzyme on organisms grown in the presence of glucose or glycerol (Fig. I). However specific conditions of the 2-DG pretreatment and snail-gut enzyme treatment had to be carefully controlled. The 2-DG pretreatment had to make the walls fragile, without leading to lysis and causing inactivation of respiration. Therefore, it has to be adapted for each strain and each culture condition. For the wild-type strain, pretreatments for $20 \mathrm{~min}$ with $100 \mu \mathrm{g}$ 2-DG/ml (YPDG medium) or $30 \mathrm{~min}$ with $250 \mu \mathrm{g} 2-\mathrm{DG} / \mathrm{ml}$ (GLU medium) were sufficient. Subsequent 
treatment with $\beta$-mercaptoethanol was always beneficial for sphaeroplast formation. Glusulase was more efficient than helicase. The optimal density during enzyme treatment was about $10^{9}$ organisms $/ \mathrm{ml}$. Above this density the efficiency of the enzyme decreased, and the use of higher enzyme concentrations did not compensate. At enzyme concentrations higher than I \%, sphaeroplasts tended to burst prematurely during enzyme treatment, despite the presence of I M-sorbitol. In order to avoid premature bursting, the enzyme treatment had to be stopped when sphaeroplast counts reached about $75 \%$ of the total. Under these conditions, sphaeroplasts obtained by the combined actions of 2-DG, $\beta$-mercaptoethanol and glusulase exhibited the same respiratory rate as intact organisms.

\section{Induction of sphaeroplasts from mutants}

The method described above was tested on four mutants modified in their respiratory properties: M I26, M53 (Goffeau, Colson, Landry \& Foury, 1972), COB5 and сов6 (Foury \& Goffeau, 1972). 2-DG induced wall lysis of all mutants except coB6. However, this last strain was very sensitive to glusulase and 2-DG pretreatment was not needed. For the other strains, 2-DG pretreatment markedly facilitated the action of glusulase. After 2-DG pretreatment, the percentage of sphaeroplasts formed by I h treatment with I \% glusulase, increased from 5 to $30 \%$ for MI 26 , from 5 to $36 \%$ for M53 and from 25 to $85 \%$ for COB5. Specific conditions of the 2-DG pretreatment had to be adapted to each mutant; I00 $\mu \mathrm{g}$ $2-\mathrm{DG} / \mathrm{ml}$ for $30 \mathrm{~min}$ was effective for glucose-grown $\mathrm{MI} 26$, whereas $500 \mu \mathrm{g} 2-\mathrm{DG} / \mathrm{ml}$ for 60 min was required for glucose-grown M53 and COB5. Short 2-DG pretreatment also facilitated sphaeroplast formation in glycerol grown-cells.

This investigation was supported by the Euratom research contract no. 086-70-10 BIO B and the NATO grant no. 564. Contribution no. 763 of the Euratom Biology Division. F.F. is a Euratom trainee.

\section{REFERENCES}

Birnboim, H. C. (1971). New method for extraction of ribonucleic acid and polyribosomes from Schizosaccharomyces pombe. Journal of Bacteriology 107, 659-663.

FOURY, F. \& GOFFEAU, A. (1972). Glucose superrepressed and derepressed respiratory mutants in a petitenegative' yeast: Schizosaccharomyces pombe $972 \mathrm{~h}^{-}$. Biochemical and Biophysical Research Communications 48, 153-160.

Goffeau, A., Colson, A. M., Landry, Y. \& Foury, F. (1972). Modifications of mitochondrial ATPase in chromosomal respiratory-deficient mutants of 'petite-negative' yeast: Schizosaccharomyces pombe $972 \mathrm{~h}^{-}$. Biochemical and Biophysical Research Communications 48, I448-1454.

Havelkova, M. (1966). A comparative study of submicroscopic structures of protoplasts of various yeast species. Folia microbiologica (Praha) Ir, 453-458.

JoHNSON, B. F. (1968). Lysis of yeast walls induced by 2-deoxyglucose at their sites of glucan synthesis. Journal of Bacteriology 95, I I69-I I 72.

Johnson, B. F. (1969). Dissolution of yeast glucans induced by 2-deoxyglucose. Experimental Cell Research 5o, 692-694.

JOHNSON, B. F. \& RUPERT, C. M. (1967). Cellular growth rates of the fission yeast, Schizosaccharomyces pombe and variable sensitivity to 2-deoxyglucose. Experimental Cell Research 48, 61 8-620.

MeGNet, R. (1965). Effect of 2-deoxyglucose on Schizosaccharomyces pombe. Journal of Bacteriology 9o, I032-I035.

Rost, K. (1969). Gewinnung und Eigenschaften von Protoplasten aus Schizosaccharomyces pombe. Zeitschrift für allgemeine Mikrobiologie 9, 289-295.

Shahin, M. M. (I97I). Preparation of protoplasts from stationary phase cells of Schizosaccharomyces pombe. Canadian Journal of Genetics and Cytology 13, 714-719. 